\title{
1 Energy transition in the Baltic Sea Region
}

\author{
Bottom-up activities, stakeholder \\ engagement and social acceptability
}

\author{
Farid Karimi and Michael Rodi
}

\section{Prologue: scope and overview}

Public acceptance, bottom-up grassroots activities and social acceptability play an essential role in an energy transition. It is therefore vital to understand how to unlock the potential for public, community and prosumer participation in a clean energy transition. This requires a closer examination of how stakeholder acceptability, in particular social acceptability, emerges. The existing literature on these topics may be extensive, but it often provides little guidance to policymakers and other actors on how to proceed with their work given the complex nature of social acceptance and acceptability.

This book analyses the potential for active stakeholder engagement and bottom-up activities in an energy transition in various sectors. Using the Baltic Sea Region (BSR) as an empirical focus, it also examines the practical implications of policy measures in order to foster clean energy deployment in the region and apply lessons learnt from this region to other areas in and outside Europe. The chapters reflect an interdisciplinary approach that draws on various disciplines within the social sciences, including political science, economics and law.

In this book, the BSR is defined as the region encompassing the following countries: Denmark, Estonia, Finland, Germany, Latvia, Lithuania, Norway, Poland, Russia and Sweden. However, the various analyses included here only refer to the European Union (EU) and European Economic Area (EEA) of the BSR. The BSR is an interesting case study which offers fertile ground for empirical testing and for the transfer of lessons learnt to other parts of Europe and around the world. This is because the region represents a microcosm of diverse energy profiles and strategies, decarbonisation approaches, cultures, political histories, and legal and industrial profiles. It has the potential to harness significant renewable energy (RE), particularly wind power (e.g., Child, Bogdanov and Breyer, 2018; Karimi and Rodi, 2021), while ensuring the flexibility of the energy system.

While the BSR shares certain characteristics associated with its natural system, the region is geographically diverse: it encompasses metropolitan areas as well as a considerable number of islands and rural regions, many of which are remote and have low population density. Moreover, landmark events in the energy transition have occurred in the region, such as the first-ever 
decommissioning of a nuclear power plant, Greifswald nuclear power station, which took place on the Baltic coast near Greifswald, Germany. This took place soon after the fall of the Berlin Wall - or, in broader terms, the fall of the Soviet Union and the Eastern Bloc, an event that ultimately led to the democratisation of the Central and Eastern European (CEE) countries of the BSR. The economic and social challenges inherited by the post-Soviet countries of the region (e.g., Mišík and Oravcová, 2021) add another interesting dimension to the empirical study of this region. The BSR also faces complex political challenges and dilemmas that, in some cases, provoke conflict. These could hinder a timely energy transition and impede the development of common strategies to combat climate change. Such challenges pertain mainly to political disputes with, and security challenges posed by, Russia, not least vis-à-vis the CEE countries of the region; this can be seen, for example, in the controversy over the Nord Stream 2 gas pipeline (e.g., Karimi and Rodi, 2021) or in recent security concerns regarding external actors like China (e.g., Scott, 2018). In light of these challenges, there is a preference and a tendency to decrease dependency on fossil fuels imported mainly from Russia (and to a lesser extent from the Middle East) and on electricity imported from Russia to the other countries of the region, including the Baltic States and Finland. Finally, the region includes a few of the countries on the list of highest $\mathrm{CO}_{2}$ emitters in the world, such as Germany and Poland (Global Carbon Atlas, 2021).

In sum, the countries of the BSR have certain notable features in common, but the region is also fragmented in many respects. These characteristics make the BSR an 'all-inclusive case' with enormous potential to inform broader debates, even beyond the region. Lessons from the BSR are particularly valuable as they suggest the potential for decentralised, bottom-up activities to serve as a complementary measure for energy independence and transition. This approach contrasts with the centralised, top-down energy transitions that tend to dominate mainstream discussions and the relevant literature.

\section{Energy transition in the Baltic Sea Region: overview and concepts}

An energy transition, as is used here, aims to decarbonise the energy system (or, broadly speaking, the economy) and secure the energy supply in order to ensure sustainable development and mitigate climate change. Such transitions entail a significant set of changes to the patterns of a society's energy use, with likely effects on resources, carriers, converters, institutions, services and behaviours (e.g., Sovacool et al., 2016). In the context of sustainable development, energy transition is a specific term used to describe a transformation of the economy from fossil-based to carbon-neutral by 2050 in an effort to mitigate climate change (European Commission, 2020a, 2020b). It is a process intended to significantly reduce global $\mathrm{CO}_{2}$ emissions in line with the objectives of both Article 2 of the Paris Agreement (UNFCCC, 2016) and the European Green Deal (European Commission, 2020a). These ambitious objectives demand clear and effective 
strategies and policies, adequate resources and funding, and cultural and behavioural changes at all levels (Karimi and Rodi, 2021).

An energy transition has technological, socio-political, legal, economic and environmental dimensions. It can be analysed at three levels: global, (macro- or micro-) regional and national. In this book, we focus on socio-political, legal and, to some extent, economic dimensions of an energy transition at a regional level (i.e., the BSR) and at the national level (i.e., individual countries of the $\mathrm{BSR})$. Although the region is fragmented in terms of energy governance and politics, it could theoretically achieve the ambitious climate policy objectives of the EU even before other regions, becoming a model for other areas (e.g., Child et al., 2018). This is mainly due to the region's enormous potential to harness RE (notably wind power, biomass and hydropower). It also has specific opportunities to increase energy system flexibility by balancing supply and demand, ensuring security of supply through energy storage options, liquefied natural gas (LNG), energy efficiency even at the household level, decarbonisation of the mobility sector and sustainable land use.

In order to expedite an energy transition, it is vital to increase the share of RE in the energy system, improve energy efficiency and ensure flexibility in energy supply and demand. These were long seen as challenges because of a lack of innovative technology and adequate funding. Technological challenges and funding issues are gradually being addressed; however, as is the case for any process of societal transformation, public participation and engagement continue to be highly relevant to the energy transition (e.g., Chilvers and Longhurst, 2016; Chilvers et al., 2021). Without public support, acceptance and participation, any societal change, including an energy transition, is doomed to failure in democratic societies.

Mainstream discussions of alternative energy policy for energy transitions tend to focus on large-scale centralised energy systems and on top-down activities and strategies. Nevertheless, it appears that promising potential and capacity exist for smaller-scale energy generators to make substantial contributions to an energy transition and to the fulfilment of EU climate goals, particularly in the BSR, which encompasses many islands and rural regions (Kotilainen, 2020; Hanger-Kopp et al., 2019; Zhang et al., 2017). Examples of small-scale systems and bottom-up grassroots activities and stakeholders include microgrids (e.g., prosumers) and community energy projects (Zhang et al., 2017; Bauwens et al., 2016; Burger and Weinmann, 2014). In other words, mobilising people to transition from being passive consumers to active 'energy citizens' would be an important guarantor of success in a new, decentralised and climate-friendly energy system. Prosumption offers an advantage to the energy system because it brings production closer to consumers and even creates green jobs in local communities. Moreover, it increases the share of renewables in power generation and decreases $\mathrm{CO}_{2}$ emissions, since $\mathrm{RE}$ is the most common alternative for prosumers. Prosumption is likely to ensure the security of supply on a micro level while increasing the energy system flexibility. Active engagement of prosumers is necessary to ensure social and economic equality and wellbeing (Chapters 7 and 


\section{Farid Karimi and Michael Rodi}

8). Flexibility, which is critical to the success of the energy transition, can be obtained from the following three sources: producers, interconnections and consumers. Thus, the challenge is to provide a level playing field for these three sources of flexibility, which have different backgrounds and driving forces, especially as consumers have generally been considered relatively insignificant relative to large producers and interconnectors.

Some see bottom-up, small-scale, grassroots activities for energy production as an opportunity to further democratise a central area of the economy (e.g., Heldeweg and Saintier, 2020) and as an alternative to energy dependency, particularly for smaller countries. Furthermore, media have generally portrayed small-scale energy generation as a policy that empowers people and civil society to directly affect their own lives and wellbeing (e.g., Pfeifer, 2018). This factor is especially important in light of the fact that, in democracies, governments generally change after four- or five-year terms; as a result, political rivalry may hinder governments from implementing concrete policies that bear fruit in the long term. In an attempt to circumvent these policies, governments may invest less in an energy transition and long-term commitments and adopt more populistic approaches that promote short-sighted policy or otherwise advance their political interests. Furthermore, if a political party in power denies climate change, or if climate policy is not central to the party's agenda, less attention is paid to the energy transition, and the entire process of the energy transition may stagnate. This can be observed, for example, in the recent political trend towards more conservative policies in some CEE countries. Thus, bottom-up, grassroots activities vis-à-vis an energy transition would, to a certain extent, ensure that the energy transition continues at a steady pace, regardless of the political orientation and policy preferences of national governments.

Perceptions, reactions and acceptance significantly affect the success of energy transitions at local, regional and global levels (Suškevičs et al., 2019; Wolsink, 2018; Chapters 4, 6 and 12). As Kojo et al. argue in Chapter 6, a decentralised energy transition can only be successful when it is accepted by the people. Social and psychological (e.g., Karimi and Toikka, 2018), economic (Chapters 4 and 6) and political (e.g., Dermont et al., 2017) factors influence social acceptance of new forms of energy production and attitudinal shifts towards energy consumption. Factors facilitating stakeholder acceptance include the presence of robust institutions, political commitment, supportive laws and regulations, competitive costs, a sophisticated communication system and comprehensive financing (Sovacool and Ratan, 2012). Incentivised policy with tangible local benefits and technical support would increase social acceptance among prosumers and microgenerators (von Wirth et al., 2018). In Chapter 3, however, Egelund Olsen argues that the design of these sorts of policies and support systems requires meticulous analysis of the effect of such measures and indicates a need for more dynamic and flexible regulatory approaches.

Although the above factors are crucial, they alone cannot fully explain the complex nature of social acceptance and the emergence of social acceptability (e.g., Krick, 2018; Devine-Wright et al., 2017; Sonnberger and Ruddat, 2017). 
To overcome the current research gap concerning patterns of stakeholder acceptance and acceptability, it is necessary to understand how social acceptance and public engagement can be activated in order to increase social acceptability. Against this background, we scrutinise the influence of small-scale, regional and bottom-up activities (rather than that of top-down and large-scale activities) on the emergence of social acceptability.

The importance of social acceptability is also crucial to the fulfilment of broader policy goals. The European Commission strives to integrate renewable energy cooperatives into the citizen-driven governance of the Energy Union. This would enable citizens to 'take ownership of the energy transition' (European Commission, 2015, p. 2). Although the European Federation of Renewable Energy Cooperatives is quite strong, it is clear that most citizens are motivated more by local circumstances than by engagement at higher policy levels (Tosun et al., 2019). Still, there is a niche for such approaches: energy cooperatives often engage in regional energy transition governance and contribute to a democratic trans-municipal governance network (Hoppe and Miedema, 2020).

Finally, an increase in the share of variable renewable energy (VRE) (and, eventually, greater energy system flexibility) will contribute to job creation and increase employment, particularly on the demand side (e.g., Füllemann et al., 2020), for instance through the emergence of new enterprises. This is likely to significantly increase the social acceptability of the energy transition. In addition, investment in research and development in related areas promises not only to expedite this process, but also to create academic jobs, thus tightening the link between university, industry and society.

\section{Stakeholder engagement and community acceptance: a missing piece of the jigsaw}

As we argue in the previous section, public attitudes towards energy solutions vis-à-vis climate change considerably affect the development and deployment of different technologies. Social acceptability is a key factor that should be considered in parallel with the development of technologies themselves. According to the Eurobarometer (2015), 91\% of people in EU countries support the EU policy to increase the share of renewable energy by 2030. However, it is important to understand the mechanism for local community participation in renewable energy deployment. Antoni and Rodi (Chapter 2) observe that people can be activated at different levels. This applies to flexibility options as well as to different opportunities to become actively engaged as producers or consumers (e.g., prosumers), either at an individual level or as part of more or less formal cooperation (e.g., companies or energy communities). At the first level, the energy transition requires increased opportunities for demand-side flexibility, which is normally controlled by third parties, generally grid providers. The provision of this service by companies as aggregators or new energy actors can be compared with commercial or industrial consumers (Leal-Arcas et al., 2018). These are already regarded as flexible consumers who often actively reduce their electricity 


\section{Farid Karimi and Michael Rodi}

demand and thus contribute to balancing supply and demand in the overall electricity system. A more important concept in the context of citizen engagement is the self-generation of energy (electricity or heat), which allows people to become energy producers ('prosumers').

Before analysing potential state and governmental approaches to increase stakeholder engagement, it is important to understand what has happened so far in this respect and which motivations activate people for the energy transition (e.g., Lennon et al., 2019). Studies show that motivations are extremely diverse (Soeiro and Ferreira Dias, 2020). Interestingly, the strongest and most common motivations are non-monetary: people feel responsible for the environment, want to influence their local community and bring people together (Kalkbrenner and Roosen, 2016). Thus, motivations to join community energy initiatives, for example, often seem to be connected to [sustainable] lifestyle (Soeiro and Ferreira Dias, 2020). People are of course also interested in business models offered by participatory schemes.

Against this background, the central research questions in this book are: what is the potential for bottom-up activities to ensure steady progress on an energy transition? What are the recent socio-political and legal developments concerning grassroots and bottom-up activities for an energy transition? Are current policies and strategies effective in decentralising energy systems and engaging people for an energy transition? What, if anything, about our current laws and regulations must be changed? Are there lessons to be learnt from the BSR as a microcosm of diverse decarbonisation, cultures, and different legal and industrial profiles? And, finally, how does social acceptability emerge in a way that would expedite an energy transition on the regional, national and international levels? Our hypothesis is that there is untapped potential for demand-side and bottom-up activities to expedite a secure energy transition, even in countries with top-down, centralised energy systems that have thus far appeared to make remarkable advancements in an energy transition and in the decarbonisation of the economy. This book draws on various case studies and interdisciplinary approaches to discuss this untapped potential and the challenges involved in translating it into action.

\section{Stakeholder engagement and community acceptance: challenges for the legal order}

Antoni and Rodi, and Egelund Olsen argue in Chapters 2 and 3 that, social, political and technological advancements can provide only partial solutions to challenges of the energy transition. The law must also provide an answer to these challenges. The legislature has the authority to determine how to promote public engagement in bottom-up activities for an energy transition, as well as to set targets in accordance with these decisions. To realise the goal of an energy transition with a special focus on decentralised and citizen-engaged activities, possible legal barriers must be identified and removed. This may not be sufficient, however, and the legislature must consider instruments to incentivise the private 
sector as well as individuals. In the EU, these decisions are taken in a fragmented multi-level legal system pertaining to EU law, national law, subnational law (e.g., laws of federal states and regions) and municipal law. To overcome the horizontal fragmentation, integrative institutions and governance systems must be designed and implemented. As EU law has not yet developed successful cooperation systems and institutions on the EU level, macro-regional strategies play an important role to fill the gap (Núñez Ferrer et al., 2019). Of these, the EU Strategy for the Baltic Sea Region (EUSBR) set up in 2009 is among the most important. ${ }^{1}$ It extended the existing Baltic Energy Market Interconnection Plan (BEMIP), developed in 2008. ${ }^{2}$

This legal design is very much in its early stages, and the current approach of the European legislatures is extremely cautious and even vague. Thus, there is a need for input from the social sciences to further shape the instruments to be implemented. For instance, in Chapter 4, Pons-Seres de Brauwer and Cohen state that legislative efforts will remain impaired without empirically validated evidence addressing the various characteristics that influence citizen participation in RE initiatives. In this chapter, an analytical examination of survey data is used to demonstrate the relative influence of national socio-economic trends, energy cultures and demographic factors on the participation of citizens as coinvestors in community energy developments providing input that legislatures can use in developing legislation.

In November 2016, the European Commission (EC) presented legislative proposals under the title 'Clean energy for all Europeans. ${ }^{3}$ The proposals of the EC were made to implement the conclusions of the European Council of October 2014 on the framework for climate and energy policy until 2030 (European Council, 2014). A significant portion of the reform covered the recasting of legal acts adopted in the framework of the Third Internal Energy Market Package of $2009,{ }^{4}$ which related to the internal electricity market and promotion of renewable energy sources (RES). The new Regulation on the internal market in electricity (Regulation (EU)2019/943 - Electricity Market Regulation or EMR) has been directly applicable in the Member States since 1 January 2020. Member States were required to implement the recast Directive on the internal electricity market (Directive (EU)2019/944 - Electricity Market Directive or EMD) by 31 December 2020 at the latest (Art. 71.1 EMD).

Digitalisation, technological progress in grid management and increased generation of RES have unlocked (new) opportunities - including the active participation of consumers - that allow for improved coordination of local supply and demand and thus help prevent regional grid bottlenecks. Because of this, 'consumers have an essential role to play in achieving the flexibility necessary to adapt the electricity system to variable and distributed renewable electricity generation,' as stated in recital 10 EMD. The EMD aims to strengthen the participation of various players in the electricity market, thereby reducing obstacles to citizen-supported supply concepts. Art. 15 EMD regulates the rights of 'active' customers, which, according to the definition in Art. 2.8 EMD, also includes prosumers. Active citizens may not be subjected to disproportionate or discriminatory 
technical and administrative requirements, procedures, levies and charges, or non-cost-oriented network charges. In accordance with European legal requirements, it is therefore likely that any equation of prosumers with energy supply companies is contrary to European law, as these are subject to disproportionate administrative requirements. Consequently, a legislature might be required to change its national regulations to be compatible with European standards.

Of equal importance is the fact that Directive (EU)2018/2001 - Renewable Energy Directive or RED II defines the rights of self-consumers in the field of renewable electricity (Art. 21 RED II) and of renewable energy communities (Art. 22 RED II) for the first time at the EU level. It defines certain framework conditions with regard to their financial burden in the form of taxes and levies, which obliges the Member States to create an enabling framework for these actors under national law by 1 July 2021 (Art. 36 RED II).

In sum, national legal orders within the EU contain an initial framework for the legal design of instruments to activate people for decentralised energy transformation, mainly in the electricity sector. It is now the responsibility of the national legislatures to translate these vague outlines into concrete measures, and it will be interesting to see how the results differ between legal orders. In Chapter 2 of this book, Antoni and Rodi explore the legal approach that the EU has taken to activate its citizens for further participation in the energy transition. The authors examine the existing conceptual legal framework for prosumers and provide an overview of the status of prosumers using the examples of Germany and Poland. The chapter suggests further steps that must be taken in the EU Member States - especially in the BSR - to implement the European framework for the active participation of citizens. In Chapter 3, Egelund Olsen discusses the legal challenges and gaps to promote local acceptance, using the Danish Renewable Energy Act as an example. She concludes that the current toolbox is not yet fully developed and that there is a need for a deeper understanding of the functions of different measures. Chapter 3 suggests that regulatory development needs to include individualised measures tailored to meet the distinct needs of local communities or individual landowners in the BSR and beyond.

In Chapter 5, Magnusson focuses on the case of community energy in Sweden and, based on a comprehensive study of the development of energy regulations and policy in Sweden, discusses how short-sighted regulatory design and a failure to consider alternative pathways would lead to path dependency and obduracy in an energy transition, even in countries with progressive energy policies like Sweden. Moreover, these pitfalls eventually hinder active citizen participation in, for instance, community energy activities and the development of decentralised RE generators.

\section{Citizens as an expediting driving force for an energy transition: policy bottlenecks, evidence and cases from the BSR countries}

One of the central objectives of this book is to examine the practical implications of current and potential policy measures and to provide recommendations 
or input for the development of the law and regulatory framework - as described above - that is a sine qua non of expediting an energy transition. To address this, in Chapter 6, Kojo et al. discuss how to move from social acceptance to social acceptability and what elements impact the acceptability of the transition, drawing on the electricity system in Finland as an example. The authors argue that, although Finland already has significant technical advancements in place for an energy transition, it must make certain changes to facilitate faster and further electrification of society and large-scale decarbonisation; the smart control of electrical loads in households will require a new business model and service concepts as well as active support from private individuals and consumers, among others.

In Chapter 7, Standal and Feenstra argue that local and individual activities for producing energy have several notable advantages: they increase the share of RE in the national energy mix, improve grid flexibility and bolster the social acceptability of RE. To promote these activities, a level playing field for all stakeholders is crucial. Because social and economic differentiation in societies might limit the potential of citizens to act (e.g., as prosumers), the concept of energy justice is a vital consideration in policymaking. This chapter employs the example of the Norwegian electricity system to explore how energy narratives reinforce and produce structures of gender and intersectional social differentiation that limit the inclusivity of the energy transition and hinder citizen energy production from becoming more mainstream.

Existing obstacles to an energy transition in the region include the sociopolitical and economic challenges that have plagued the post-Soviet countries of the region in their transition to democratic regimes and their recovery from communist systems (e.g., Gál, 2021). These countries suffered significant economic damage as a result of the collapse of major industries following the fall of the Communist regimes. Still, many of these, especially Poland, have developed a relatively strong economy. This has led to a reliance on a fossil-fuel-based, centralised energy system that hinders an energy transition. In some cases, it has also led countries to set less ambitious energy and climate goals (relative to their Western European counterparts) on the grounds that, in order for the economic level of such countries to equal that of Western EU states, 'the load [of ambitious EU climate and energy policy] carried by individual members should correspond to their economic performance and should not jeopardize their competitiveness' (Mišík and Oravcová, 2021, p. 8). Therefore, the role of Poland as one of the largest $\mathrm{CO}_{2}$ emitters in the region (after Russia and Germany) is notable in the context of the energy transition. Against this background, Chapter 8 articulates a comprehensive post-Communist system transition in Poland vis-à-vis the energy transition, with a focus on the revitalisation process in the rural and semi-rural areas of Pomerania. Pietrzykowski, Rembarz and Cenian highlight the crucial roles of a bottom-up approach, with contributions from activists, scientists and entrepreneurs, in the revitalisation of less privileged regions. The authors assert that, although EU funds are extremely helpful enablers, local-level innovation cannot be limited to the adaptation of solutions from other environments to local conditions. 


\section{Farid Karimi and Michael Rodi}

Chapter 9 analyses Polish energy clusters that aim to meet the energy needs of local communities while mobilising people to become actively involved in clean energy production. Surwillo argues that, due to stagnation in the wind energy sector in recent years and delays in establishing the first renewable energy sources (RES) cooperatives, there is a need for new business models that can accommodate bottom-up citizen initiatives in Poland to meet energy demand and achieve the EU energy and climate goals. This chapter explores some of the factors in the initial success of pilot energy clusters, as well as the challenges faced.

The transport and building sectors are among significant $\mathrm{CO}_{2}$ emitters, with a share of $33 \%$ in total (IEA, 2021). Thus, these two sectors play a crucial role in the energy transition and in the decarbonisation of the economy. Chapters 10 and 11 examine these two sectors. First, Laakso and Lukkarinen refer to an example from Finland to discuss the practices that housing cooperatives have implemented to encourage engagement with sustainable energy in buildings, which affect the implementation of more ambitious climate policies. Chapter 10 argues that the critical practices from the perspective of energy policy are not necessarily related to energy per se but to ways of decision-making, providing and utilising information, planning and communication with the actors. The authors recommend policy interventions that focus on embedding sustainability considerations in these practices to facilitate a timely energy transition in buildings. For instance, it is worthwhile to introduce new incentive structures prioritising sustainable energy improvements and linking them more directly to management practices in buildings, as this can encourage housing cooperatives to integrate sustainability into their decision-making processes.

With regard to the transport and mobility sector, Sareen et al. shed light on the bifurcated challenge facing urban planners and policymakers: the swift decarbonisation of mobility and the legitimisation of these measures vis-à-vis a diverse public. Based on a case study of the city of Bergen, Norway, the authors argue that the mobility transition is mainly influenced by divergent socio-technical imaginaries of mobility among commuting publics. Thus, planners should consider these and change the embodied routines of transition planning and implementation to conform to a socially inclusive mobility future. This must be followed by legitimate participatory planning activities with input from relevant stakeholders. Finally, the authors contend that the rapid growth in electric vehicle (EV) adoption opens up low-carbon mobility transitions to the risk of an elitist 'green buyout,' whereby relatively wealthy households can persist with automobility practices while moving away from fossil fuel cars. The authors recommend that shifts to EVs thus be accompanied by a continued phase-out of car parking spaces, an increase in car-sharing schemes and a commitment to making the public transport system the most convenient and affordable transport option.

This book includes insights from a 'neighbour' of the BSR to indicate what the BSR can learn from an EU country outside the BSR and to compare states of affairs in the BSR and an EU country outside its borders. Thus, Chapter 12 provides 'external' insight into the topic of the book to enhance the comparative rigour of the book. Komendantova, Neumueller and Nkoana argue that climate 
change mitigation goals and energy security policies would lead to societal transformations, particularly due to the large-scale deployment of new technologies or changes related to the generation, distribution and transmission of electricity. The goals are often set at the national level of government, but their implementation occurs at a local level of government. As a result, the energy transition process should include measures to encourage the active engagement of inhabitants and local governments while providing a chance for the public to participate in decision-making processes that affect their lives. This chapter explores behaviour and motivation structures within different user groups in the energy transition process based on empirical case studies in Austria. The authors describe how lessons learnt in this region can inform policy and practice in the countries of the BSR. One of the main conclusions of the chapter confirms the key role of communication with the local public concerning the transformation of the energy system. Communication should be tailor-made to the needs of each social group and carried out through trusted communication channels. There is also a need for a greater understanding of the potential role that engagement can play in an energy transition, as well as the possibilities that already exist and the specific stages of the decision-making processes in which the public wishes to be engaged.

The final chapter, Chapter 13, discusses the main conclusions of the book and explains the potential role of the BSR as a laboratory for an energy transition. It also summarises policy recommendations of the book and provides suggestions for further research.

Each chapter describes impediments to mobilisation, as well as agency and theory. Although the broader focus of this book is on practical implications, the chapters advance theory-building slightly with a framework or discussion that connects theories. This book includes four parts. 'Part I: stakeholder engagement and acceptance: a legal framework' identifies legal gaps and requirements for facilitating stakeholder engagement and social acceptance in an energy transition. In 'Part II: energy policy for engaging people for an energy transition in the Baltic Sea Region,' some of the existing policy measures are evaluated in terms of their effectiveness and impact, and the policy requirements for expediting citizen initiatives are discussed. 'Part III: flexibility options for demand-side, social acceptance and community engagement - case studies' uses various empirical studies to examine different approaches to social acceptability and grassroots activities. Finally, 'Part IV: insights from other sectors and regions' assesses an energy transition in other major sectors, such as the building and transport sectors, as well as what can be learnt from a 'neighbour' of the BSR.

\section{Notes}

1 Council of the European Union, Brussels, 30 October 2009, 15265/09, concl 3; www .balticsea-region-strategy.eu.

2 https://ec.europa.eu/energy/sites/ener/files/documents/2009_bemip_mou_signed.pdf.

3 https://ec.europa.eu/energy/topics/energy-strategy/clean-energy-all-europeans_en.

4 https://ec.europa.eu/energy/topics/markets-and-consumers/market-legislation/third -energy-package_de. 


\section{Farid Karimi and Michael Rodi}

\section{References}

Bauwens, T., Gotchev, B., Holstenkamp, L., 2016. What drives the development of community energy in Europe? The case of wind power cooperatives, Energy Research E. Social Science, Energy Transitions in Europe: Emerging Challenges, Innovative Approaches, and Possible Solutions 13, Amsterdam: Elsevier, pp. 136-47. DOI:10.1016/j. erss.2015.12.016

Burger, C., Weinmann, J., 2014. Germany's decentralized energy revolution, in: Sioshansi, F.P. (Ed.), Distributed Generation and Its Implications for the Utility Industry. Boston: Academic Press, pp. 49-73. DOI:10.1016/B978-0-12-800240-7.00003-5

Child, M., Bogdanov, D., Breyer, C., 2018. The Baltic Sea region: Storage, grid exchange and flexible electricity generation for the transition to a $100 \%$ renewable energy system, Energy Procedia, 12th International Renewable Energy Storage Conference, IRES 2018, 13-15 March 2018, Düsseldorf, Germany 155, pp. 390-402. DOI:10.1016/j. egypro.2018.11.039

Chilvers, J., Bellamy, R., Pallett, H., Hargreaves, T., 2021. A systemic approach to mapping participation with low-carbon energy transitions, Nature Energy 6, London: Springer Nature, pp. 250-9.

Chilvers, J., Longhurst, N., 2016. Participation in transition(s): Reconceiving public engagements in energy transitions as co-produced, emergent and divers, Journal of Environmental Policy $\mathcal{B}$ Planning 18, Abingdon: Taylor \& Francis, pp. 585-607.

Dermont, C., Ingold, K., Kammermann, L., Stadelmann-Steffen, I., 2017. Bringing the policy making perspective in: A political science approach to social acceptance, Energy Policy 108, Amsterdam: Elsevier, pp. 359-68. DOI:10.1016/j.enpol.2017.05.062

Devine-Wright, P., Batel, S., Aas, O., Sovacool, B., Labelle, M.C., Ruud, A., 2017. A conceptual framework for understanding the social acceptance of energy infrastructure: Insights from energy storage, Energy Policy 107, Amsterdam: Elsevier, pp. 27-31. DOI:10.1016/j.enpol.2017.04.020

Eurobarometer, 2015. Citizen support for climate action. Online: https://ec.europa.eu/ clima/citizens/support_en (Accessed: 5.5.2017).

European Commission, 2015. Communication: A framework strategy for a resilient energy union with a forward-looking climate change policy, COM 80 final, pp. 1-21.

European Commission, 2020a. A European green deal. Online: https://ec.europa.eu/info/ strategy/priorities-2019-2024/european-green-deal_en (Accessed: 4.16.2020).

European Commission, 2020b. Proposal for a REGULATION OF THE EUROPEAN PARLIAMENT AND OF THE COUNCIL establishing the framework for achieving climate neutrality and amending regulation (EU) 2018/1999 (European Climate Law).

European Council, 2014. Conclusions on 2030 climate and energy policy framework, SN 79/14. Online: https:/www.consilium.europa.eu/uedocs/cms_data/docs/pressdata/en/ ec/145356.pdf

Füllemann, Y., Moreau, V., Vielle, M., Vuille, F., 2020. Hire fast, fire slow: The employment benefits of energy transitions, Economic Systems Research 32, Abingdon: Taylor \& Francis, pp. 202-20. DOI:10.1080/09535314.2019.1695584

Gál, Z., 2021. From economic transformation to energy transition: The legacy of thirty years of post-communist development, in: Mišík, M., Oravcová, V. (Eds.), From Economic to Energy Transition: Three Decades of Transitions in Central and Eastern Europe. Cham: Palgrave Macmillan, pp. 29-61.

Global Carbon Atlas, 2021. CO2 emissions. Global Carbon Atlas. Online: http://www .globalcarbonatlas.org/en/CO2-emissions (Accessed: 7.11.2021). 
Hanger-Kopp, S., Lieu, J., Nikas, A., 2019. Narratives of Low-Carbon Transitions: Understanding Risks and Uncertainties, 1st edition (Hardback). ed. Routledge Studies in Energy Transitions. Abingdon: Routledge.

Heldeweg, S., 2020. Renewable energy communities as "socio-legal institutions": A normative frame for energy decentralisation? Renewable and Sustainable Energy Reviews 119, Amsterdam: Elsevier, p. 1.

Hoppe, T., Miedema, M., 2020. A governance approach to regional energy transition: Meaing, conceptualisation and practice, Sustainability 12, Basel: MDPI, p. 915.

IEA, 2021. Global energy-related CO2 emissions by sector - IEA, Paris. Online: https:// www.iea.org/data-and-statistics/charts/global-energy-related-co2-emissions-by-sector (Accessed: 7.11.2021).

Kalkbrenner, B.J., Roosen, J., 2016. Citizens' willingness to participate in local renewable energy projects: The role of community and trust in Germany, Energy Research and Social Science 13, Amsterdam: Elsevier, pp. 60-70.

Karimi, F., Rodi, M., 2021. Energy-transition challenges in the Baltic Sea Region: An overview of socio-political and legal gaps, in: Mišík, M., Oravcová, V. (Eds.), From Economic to Energy Transition: Three Decades of Transitions in Central and Eastern Europe, Energy, Climate and the Environment. Cham: Springer International Publishing, pp. 457-87. DOI:10.1007/978-3-030-55085-1_16

Karimi, F., Toikka, A., 2018. General public reactions to carbon capture and storage: Does culture matter? International Journal of Greenhouse Gas Control 70, Amsterdam: Elsevier, pp. 193-201. DOI:10.1016/j.ijggc.2018.01.012

Kotilainen, K., 2020. Perspectives on the Prosumer Role in the Sustainable Energy System. Tampere: Tampere University.

Krick, E., 2018. Ensuring social acceptance of the energy transition. The German government's 'consensus management' strategy, Journal of Environmental Policy E Planning 20, Abingdon: Taylor \& Francis, pp. 64-80. DOI:10.1080/15239 08X.2017.1319264

Leal-Arcas, R., Lesniewska, F., Proedrou, F., 2018. Prosumers as new energy actors, Chapter 12, in: Mpholo M., Steuerwald D., Kukeera T. (eds), Africa-EU Renewable Energy Research an Innovation Symposium 2018. Cham: Springer, pp. 139-51. DOI:10.1007/978-3-319-93438-9_12

Lennon, B., Dunphy, N.P., Sanvicente, E., 2019. Community acceptability and the energy transition: A citizens' perspective, Energy, Sustainability and Society 9(35), Cham: Springer, pp.1-18.

Mišík, M., Oravcová, V., 2021. From Economic to Energy Transition: Three Decades of Transitions in Central and Eastern Europe, 1st ed, Energy, Climate and the Environment. Cham: Palgrave Macmillan.

Núñez Ferrer, J., Cătuţi, M., Stroia, C., Bryhn, J., 2019. Comparative study on the governance structure and energy policies in EU macro-regional strategies, CEPS Research Report No. 2019/02, June.

Pfeifer, S., 2018. Community energy projects bring power to the people. Online: https://www.ft.com/content/c283a8a0-5f5e-11e8-9334-2218e7146b04 (Accessed: 1.23.2020).

Scott, D., 2018. China and the Baltic States: Strategic challenges and security dilemmas for Lithuania, Latvia and Estonia, Journal on Baltic Security 4, Tartu: Baltic Defence College, pp. 25-37. DOI:10.2478/jobs-2018-0001

Soeiro, S., Ferreira Dias, M., 2020. Community renewable energy: Benefits and drivers, Energy Reports 6, Amsterdam: Elsevier, pp. 134-40. 


\section{Farid Karimi and Michael Rodi}

Sonnberger, M., Ruddat, M., 2017. Local and socio-political acceptance of wind farms in Germany, Technology in Society 51, Amsterdam: Elsevier, pp. 56-65. DOI:10.1016/j. techsoc.2017.07.005

Sovacool, B., Brown, M., Valentine, S., 2016. Fact and Fiction in Global Energy Policy: Fifteen Contentious Questions. Baltimore: Johns Hopkins University Press.

Sovacool, B.K., Lakshmi Ratan, P., 2012. Conceptualizing the acceptance of wind and solar electricity. Renewable and Sustainable Energy Reviews 16, Amsterdam: Elsevier, pp. 5268-79. DOI:10.1016/j.rser.2012.04.048

Suškevičs, M., Eiter, S., Martinat, S., Stober, D., Vollmer, E., de Boer, C.L., Buchecker, M., 2019. Regional variation in public acceptance of wind energy development in Europe: What are the roles of planning procedures and participation? Land Use Policy 81, Amsterdam: Elsevier, pp. 311-23. DOI:10.1016/j.landusepol.2018.10.032

Tosun, J., Zöckler, L., Rilling, B., 2019. What drives the participation of renewable energy cooperatives in European energy governance? Politics and Governance 7, Lisbon: Contiago, pp. 45-59.

UNFCCC, 2016. The Paris agreement. UNFCCC. Online: https://unfccc.int/process-and -meetings/the-paris-agreement/the-paris-agreement (Accessed: 3.12.2020).

von Wirth, T., Gislason, L., Seidl, R., 2018. Distributed energy systems on a neighbourhood scale: Reviewing drivers of and barriers to social acceptance, Renewable and Sustainable Energy Reviews 82, Amsterdam: Elsevier, pp. 2618-2628. DOI:10.1016/j. rser.2017.09.086

Wolsink, M., 2018. Social acceptance revisited: Gaps, questionable trends, and an auspicious perspective, Energy Research $\mathcal{E}$ Social Science 46, Amsterdam: Elsevier, pp. 287-95. DOI:10.1016/j.erss.2018.07.034

Zhang, J., Huang, L., Shu, J., Wang, H., Ding, J., 2017. Energy management of PV-dieselbattery hybrid power system for island stand-alone micro-grid, Energy Procedia, 8th International Conference on Applied Energy, ICAE2016, 8-11 October 2016, Beijing, China 105, pp. 2201-6. DOI:10.1016/j.egypro.2017.03.622 